Journal of Energy and
Environmental Sustainability (ISEES)
Journal homepage : www.jees.in

\title{
Effect of Compression Ratio on the Performance of a Constant Speed Spark Ignition Engine Operating on Raw Biogas
}

\author{
Santosh Kumar Hotta ${ }^{1 *}$, Niranjan Sahoo ${ }^{2}$, Kaustubha Mohanty ${ }^{3}$, Pinakeswar Mahanta ${ }^{2}$ \\ ${ }^{1}$ Centre for Energy, Indian Institute of Technology Guwahati, Guwahati - 781 039, India \\ ${ }^{2}$ Dept. of Mech. Engineering, Indian Institute of Technology Guwahati, Guwahati-781039, India \\ ${ }^{3}$ Dept. of Chem. Engineering, Indian Institute of Technology Guwahati, Guwahati-781039, India
}

\section{A R T I C L E I N F O}

Received : 13 February 2018

Revised : 24 April 2018

Accepted : 25 April 2018

Keywords:

SI Engine, Biogas, Performance Analysis

\begin{abstract}
A B S T R A C T
In the present investigation, experiments were conducted in a $4.4 \mathrm{~kW}$, single cylinder, water cooled constant speed, spark ignition (SI) engine fuelled with raw biogas. The engine was operated at four different compression ratios $(10.52,11.94,13.96$ and 15.29) and within a load range of 6 to $77 \%$. The effect of load level on the performance and emission characteristic of the engine at different compression ratios are analysed and presented in this paper. The brake power producing capability of the engine corresponds to CR 15.29 was maximum and found to be $2.93 \mathrm{~kW}$ with $76.27 \%$ of brake load. With increasing CR the engine becomes more stable and operates with an appreciable deviation in speed. Irrespective of engine loading condition, the minimum $\mathrm{HC}$ and $\mathrm{CO}$ emissions were noticed at $\mathrm{CR} 15.29$ and found to very between $23-144 \mathrm{ppm}$ and $0.016-0.091 \%$, respectively. The maximum NOx emission was detected at CR 15.29 and was found to very between $27-240$ ppm.
\end{abstract}

\section{Introduction}

The increasing concern of energy security and environmental protection has stimulated the active research on improving fuel economy and reducing exhaust emission. To address this issues, the major research aspects of combustion and engine development has attracted the development of alternative fuelled engines. Liquid fuels like alcohols and vegetable oils, gaseous fuels such as natural gas, liquefied petroleum gas (LPG), hydrogen, biogas, and producer gas are promising alternative fuels [Chandra et al., 2011]. Very low levels of pollutant emission were reported when gaseous fuels are effectively utilized in spark ignition (SI) and compression ignition (CI) engines [Porpatham et al., 2012]. Gaseous fuels are quite acceptable for IC engine because of their wider range of flammability limit, higher hydro carbon ratio and capability to form homogeneous mixture [Porpatham et al., 2013, 2008]. Biogas is one such a renewable fuel and attractive source of energy produced from anaerobic digestion of organic matters. It consists of approximately 50$70 \%$ of methane $\left(\mathrm{CH}_{4}\right), 25-50 \%$ of carbon dioxide $\left(\mathrm{CO}_{2}\right), 1-5 \%$ of hydrogen $\left(\mathrm{H}_{2}\right), 0.3-3 \%$ of nitrogen $\left(\mathrm{N}_{2}\right)$ and traces of other impurities, notably hydrogen sulfide $\left(\mathrm{H}_{2} \mathrm{~S}\right)$ [Nathan et al., 2010, Hotta et al., 2015]. Typically, it consists of $60 \%$ of $\mathrm{CH}_{4}$ and $40 \%$ of $\mathrm{CO}_{2}$ [Crookes et al., 2006, Hung et al., 1998]. The auto ignition temperature of biogas is very high, hence, it resist knocking which is desirable in SI engine [Porpatham et al., 2008, 2012 and 2013]. Since biogas has a higher anti nock index, biogas fueled SI engine can sustain high compression ratio (CR), which enhances the thermal efficiency of the engine [Porpatham et al., 2007].
The performance and efficiency of a SI engine is mainly dependent on the combustion phasing and is influenced by factors such as compression ratio (CR), spark advance (SA) or ignition advance (IA), air-fuel ratio (AFR), exhaust gas recirculation (EGR), variable valve timing (VVT), combustion chamber design and composition of the fuel [Alagumalai et al., 2014, Corti et al., 2014]. Out of which CR is the most important parameter for optimizing the efficiency, emission and permitting combustion engines to conform future emission targets and standards. Proper control of ignition advance timing and CR can significantly improve the exhaust emission and the performance parameters for various kinds of operating fuels in IC engines [Mitzlaff, 1988]. Increased compression ratios is an effective means of increasing the performance of biogas fueled engine when $\mathrm{CO}_{2}$ is present in the biogas. However, the break mean effective pressure and break thermal efficiency increases steadily with compression ratios up to a critical value of 13:1 [Huang et al., 1998]. Operating with a variable compression ratio (VCR) Ricardo E6 single cylinder SI engine fueled with simulated biogas Hung and Crooks reported the effect of compression ratio with RAFR and carbon dioxide fraction of 0.97 and $37.5 \%$, respectively. As reported break mean effective pressure (BMEP) and break thermal efficiency (BTE) values increase steadily with compression ratio up to a critical value of $13: 1$, above which there is a slight increase in these values. Although there is a slight increase in the BMEP along with the increase in the CR above 13:1, the additional indicated power (IP) do not compensate the mechanical losses arises due to friction. The traces of detonation were also observed at CR 15:1 [Surata et al., 2014]. In case of biogas fueled engine, the CR that can be

\footnotetext{
*Corresponding Author: h.santosh@iitg.ernet.in
} 
employed should be higher than normal SI engine as the $\mathrm{CO}_{2}$ present suppresses the knock. CR ranging from 11:1 to 13:1 reported suitable for operation without knock [Porpatham et al., 2008]. SI engine operated with biogas contains significant amount of $\mathrm{CO}_{2}$ and $\mathrm{N}_{2}$ which decreases the performance and increases the NOx emission as compared with natural gas and gasoline fueled engine [Kapdi et al., 2005].

In view of the current demand of energy utilization, fuel crisis, waste to energy conversion techniques and search of renewable resource of energy, the use of raw biogas as a standalone fuel in SI engine seems to be a good alternative solution. In order to make the raw biogas fueled SI engine more energy efficient, a detail investigation has been carried out to understand the effect of $\mathrm{CR}$ on the performance, combustion and emission characteristics of raw biogas fueled SI engine operating with a $\mathrm{CR}$ ranging from CR 10.52 to CR 15.29.

\section{Experimental Details}

\subsection{Selected fuel and their properties}

The raw biogas selected for the evaluation of the engine performance was produced by anaerobic digestion of cow dung and lignocellulos biomass in a Dinabandhu modeled biogas digester of 3 cubic meter capacity. The biogas produced from the digester was collected and stored in a neoprene coated rubber fabric balloons connected in series. The stored biogas is then supplied to the engine by flexible pipes. The composition of the used fuel is analyzed each time before testing by Thermo Fisher Scientific make gas chromatograph (GC). It has been observed that there is no substantial change in the composition of the produced biogas unless until there is drastic change in environmental operating parameters or change in feed materials to the biogas digester. However, there is a little variation in the composition of the biogas with time according to the activities of the anaerobic bacteria. Table 1, describes the composition and some of the important properties of biogas used in the experiment.

Table 1. Properties of the used fuel

\begin{tabular}{ll}
\hline Properties & Biogas \\
\hline & $\mathrm{CH}_{4}-55.6 \%{ }^{\#}$, \\
Composition & $\mathrm{CO}_{2}-42.3^{\#}$ \\
& $\mathrm{~N}_{2}-2.1^{\#}$ \\
\hline Density at $15^{0} \mathrm{C}(\mathrm{kg} / \mathrm{m} 3)$ & $1.11^{\#}$ \\
\hline Lower heating value $(\mathrm{MJ} / \mathrm{kg})$ & $17^{\#}$ \\
\hline Heat of vaporization $(\mathrm{MJ} / \mathrm{kg})$ & 0.5 \\
\hline Stoichiometric A/F ratio & $5.67^{*}$ \\
\hline Research octane number & $110^{[12]}$ \\
\hline Auto ignition temperature $\left({ }^{\circ} \mathrm{C}\right)$ & $650^{[12]}$ \\
\hline Flame Speed $(\mathrm{cm} / \mathrm{s})$ & $25^{[12]}$ \\
\hline
\end{tabular}

* Calculated \# Experimental value

\subsection{Experimental engine test rig}

The experimental setup shown in Fig. 1 consists of a Prakash made single cylinder, 990.6 CC, four stroke, water-cooled, constant speed, SI engine of rated power and speed of $4.4 \mathrm{~kW}$ and $1500 \mathrm{rpm}$, respectively. The engine was equipped with a unique governing system and a T-type mixture along with two throttle valve to control the mass flow rate of air and air-biogas mixture (as shown in Fig. 2) at all operating load to maintain the engine speed constant. The engine was coupled with a single phase, $3.5 \mathrm{kVA}$ alternator to generate $230 \mathrm{~V}$ and $50 \mathrm{~Hz}$ frequency at $1500 \mathrm{rpm}$. For loading the engine crank shaft the output of the alternator was connected with a load panel consisting of 15 numbers of 200 Watt bulbs in series. To track the consumed current and output voltage of the alternator at a particular loading condition of the engine a voltmeter and an ammeter was connected inline before the load panel. The rated CR of the engine was 13.94 for biogas mode operation. But for the sake of analyzing the effect of CR on the performance and emission characteristics of a biogas fuelled constant speed SI engine, the CR ratio of the engine was varied manually by altering the clearance volume of the engine. Since the stroke volume (939.69 CC) and the piston cavity (51 CC) were known, the engine CR without any clearance slot was found to be 19.38. Therefore by adding copper slots of $2.65 \mathrm{~mm}$ thick and bakelite slots of $1.8 \mathrm{~mm}$ thick at different combinations the $\mathrm{CR}$ of the engine was varied for each test. The performance tests of the engine were conducted at four different CRs i.e., CR 10.52, CR 11.96, CR 13.94 and CR 15.29. The engine was well instrumented to track down the operating parameters. The load on the engine was varied by applying electrical load on the alternator. For measuring the biogas flow rate a biogas flowmeter (make: Siya Instruments, Model SI-6) was used. An air box was fabricated along with an orifice of $20 \mathrm{~mm}$ diameter and connected with an open $\mathrm{U}$ tube manometer; the pressure difference in the manometer column was later used to calculate the air mass flow rate. A diaphragm type piezo pressure sensor along with built in amplifier and no noise cable was mounted on the engine head to measure the cylinder pressure during combustion. The optical crank angle encoder attached to the engine delivers a signal for each degree rotation of the crankshaft. The pressure and crank angle signals are then interfaced to the computer through piezo power unit to observe the pressure and crank angle signals as well as to measure the speed of the engine. The engine is connected to the Labview based software "Enginesoft" to record and analyze the data stored via a NI USB 6210 data logger. The emission analysis is carried out by using AVL DIAGAS $444 \mathrm{~N}$ five-gas analyzer.

\section{Results and Discussions}

The performance and emission characteristics of a constant speed biogas fueled SI engine were evaluated for varying load conditions at four different compression ratios ranging from CR 10.52 to CR 15.29. The effect of compression ratio on the performance, and emission characteristics of the raw biogas fuelled SI engine were analysed carefully throughout the operating load range and explained in the below mentioned sections.

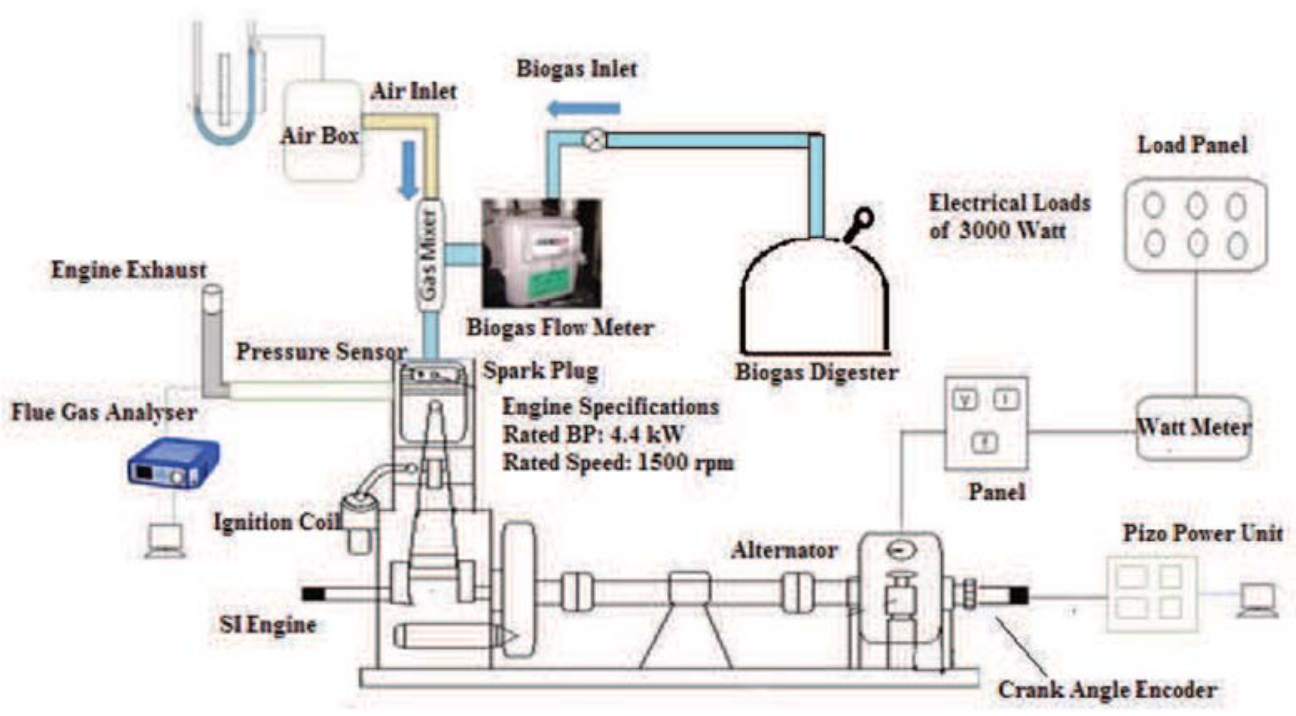

Fig. 1 Schematic layout of experimental test rig 


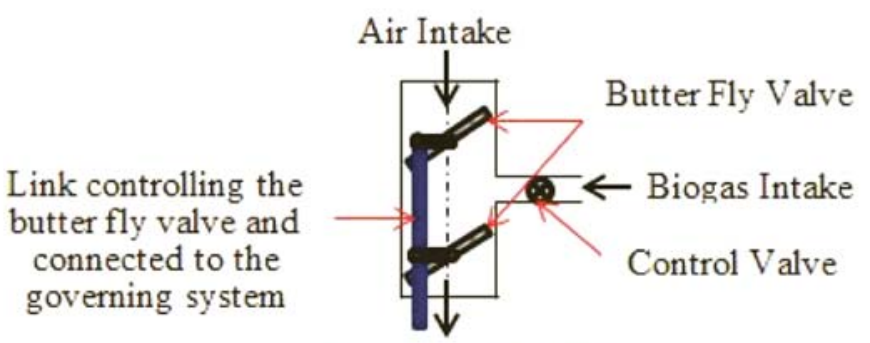

Air-Biogas Mixture

Fig. 2 Air intake and fuel mixing system

\subsection{Performance analysis}

Figure 3 shows the correlation between brake load (\%) and brake power $(\mathrm{BP})(\mathrm{kW})$ developed by the raw biogas fuelled SI engine operated with compression ratios of 10.52,11.96, 13.94 and 15.92. The spark timings for each compression ratios were set to MBT before conducting each test. As observed, irrespective of the CR, the BP developed by the engine was increasing with progressive development of the brake load on the engine. Since the developed speed of the engine irrespective of CRs are almost constant, the developed brake torque will increasing with increasing brake load, as a result of which BP of the engine will increase with progressive development of brake load on the engine. As shown in

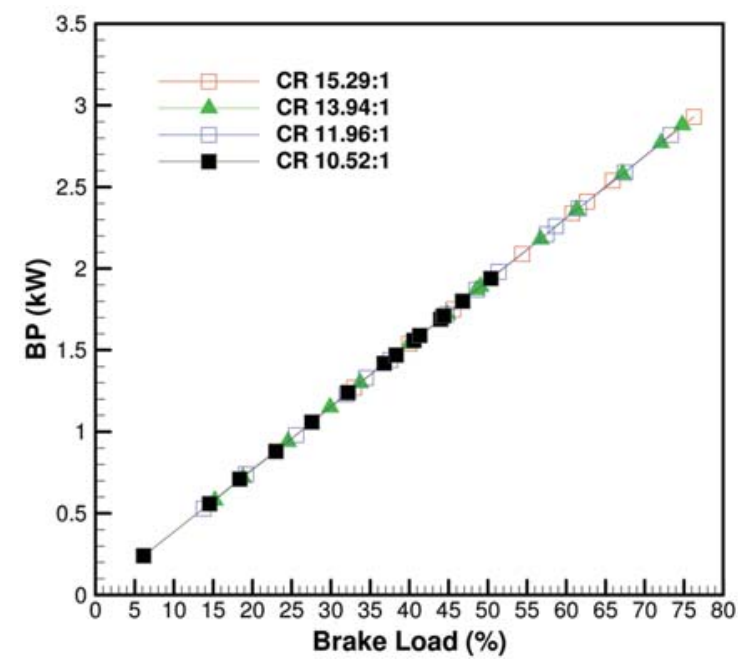

Fig. 3 Effect of CR on the BP developed by the engine

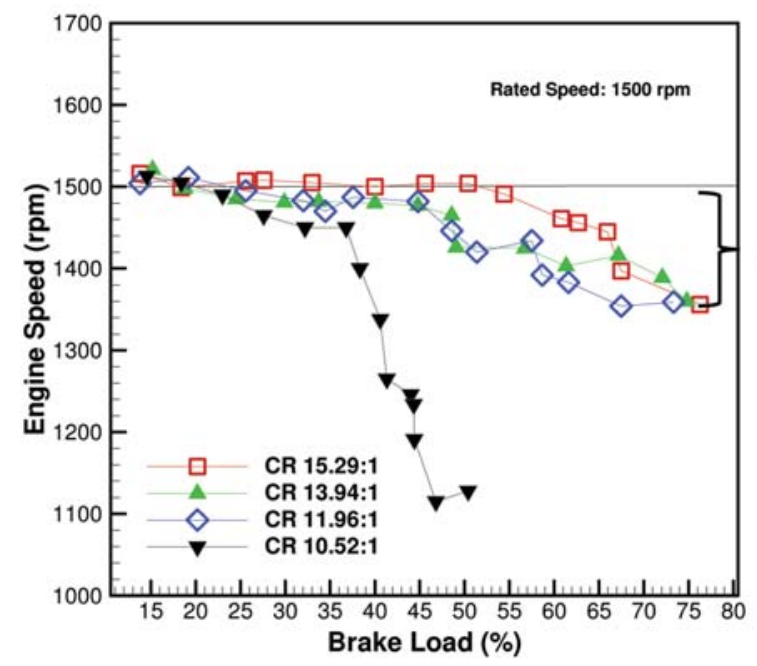

$9.3 \%$

Fig. 4 Effect of $\mathrm{CR}$ on the developed speed of the engine
Fig. 7 and 8 , with increasing brake load, the mass flow rate of the fuel consumed and the volumetric efficiency of the engine are increasing to maintain the rated speed of the engine constant. This may be the key reason for increasing $\mathrm{BP}$ with increasing brake load on the engine. It was also observed that with increasing $\mathrm{CR}$ the maximum $\mathrm{BP}$ output of the engine was increased along with enhanced brake load carrying capacity of the engine. Higher CR increases the mean gas temperature (MGT) and initiates the complete combustion and leads to higher energy conversion efficiency and develops more power.

The maximum and the minimum BP output of the engine were noticed at CR 15.29 and CR 10.52, respectively. The maximum brake power output of the engine operated at CR 10.52, CR 11.96, CR 13.94 and CR 15.29 were found to be $1.94,2.82,2.88$, and $2.93 \mathrm{~kW}$ with maximum brake load development of $50.40 \%, 73.33 \%, 74.80 \%$ and $76.27 \%$, respectively. Increasing the CR from CR 10.52 to CR 11.96 , CR 11.96 to CR 13.94 and CR 13.94 to CR 15.29 increases the maximum BP output of the engine by $45 \%, 2 \%$, and $1.95 \%$ respectively. However, the observed power reduction of the engine when operated with raw biogas were found to be $55.9 \%, 35.9 \%, 34.5 \%$ and $33.4 \%$ at CR 10.52 , CR 11.96, CR 13.94 and CR 15.29 , respectively. Similar results have been reported by R. Chandra et al., (2011) and Kapdi, S. S (2005), the power reduction of a $\mathrm{CI}$ engine when converted to a biogas fuelled SI engine was found to $46.3 \%$ at CR 12.65 .

The variations of the engine speed developed by the biogas fuelled SI engine operated at different CRs are shown in Fig. 4. It was observed that with progressive development of the engine load the speed of the engine starts deviating from its rated speed. However, these deviations are quite acceptable in CR 15.29 , CR 13.96 and CR 11.94 where, the maximum deviation is only $9.3 \%$ from the rated speed. It was noticed that at CR 15.29 , CR 13.96 and CR 11.94 the engine speed remains almost constant $(1500 \pm 50 \mathrm{rpm})$ up to $50 \%$ of the developed brake load and starts deviating after wards. The reason that could fit to explain the above happening may be the inefficiency of the governing system attached to the engine, which could not supply the accurate air-fuel mixture to the engine beyond $50 \%$ engine load. But, at CR $10.52 \%$ the engine speed was found decreasing with increasing brake load on the engine. However, the minimum speed observed was $1128 \mathrm{rpm}$ at $50 \%$ engine load and was the maximum developed brake load at CR 10.52. Similar trend was also noticed by R. Chandra et al., (2011). With increasing CR the engine becomes more stable and operated with an appreciable deviation in speed.

Figure 5 shows the correlation between the brake specific fuel consumption (BSFC) and brake load of the biogas fuelled SI engine at different operating CRs. It was evident from the figure that, irrespective of $\mathrm{CR}$, the brake specific fuel consumption follows a decreasing trend along with the increasing brake load of the engine. This is because, with increasing brake load, the rate of rise in $\mathrm{BP}$ is higher than the rate of rise in mass of fuel consumed. It was also observed that the BSFC of the engine follows a decreasing trend along with progressive development of the operating CR. The biogas engine operated at CR 15.29, CR 13.94, CR 11.96 and CR 10.52 showed the maximum BSFC of $5.29 \mathrm{~kg} / \mathrm{kWh}$, $5.17 \mathrm{~kg} / \mathrm{kWh}, 5.83 \mathrm{~kg} / \mathrm{kWh}$ and $5.53 \mathrm{~kg} / \mathrm{kWh}$ at the brake loads of $13.8 \%, 15.20 \%, 13.8 \%$ and $14.57 \%$, respectively. However, the minim BSFC of the engine operated at CR 15.29, CR 13.94, CR 11.96 and CR

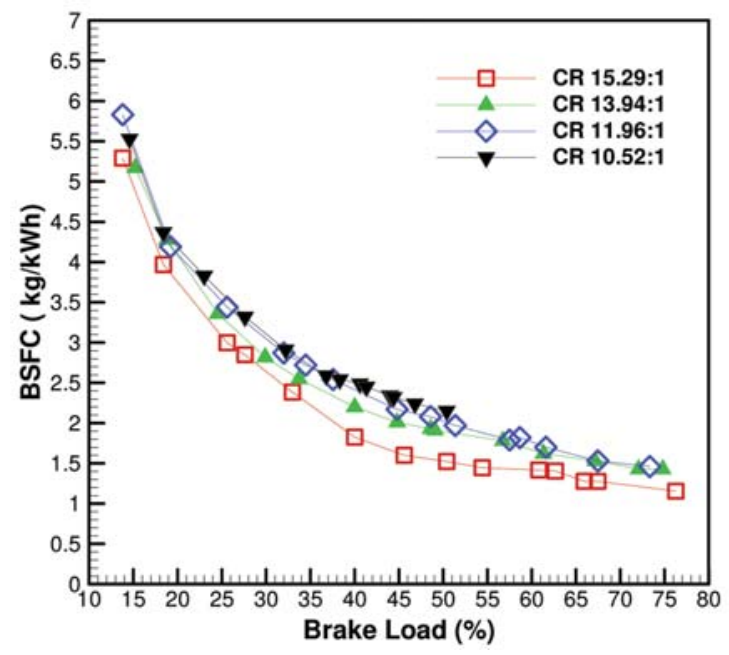

Fig. 5 Effect of CR on the BSFC of the engine 


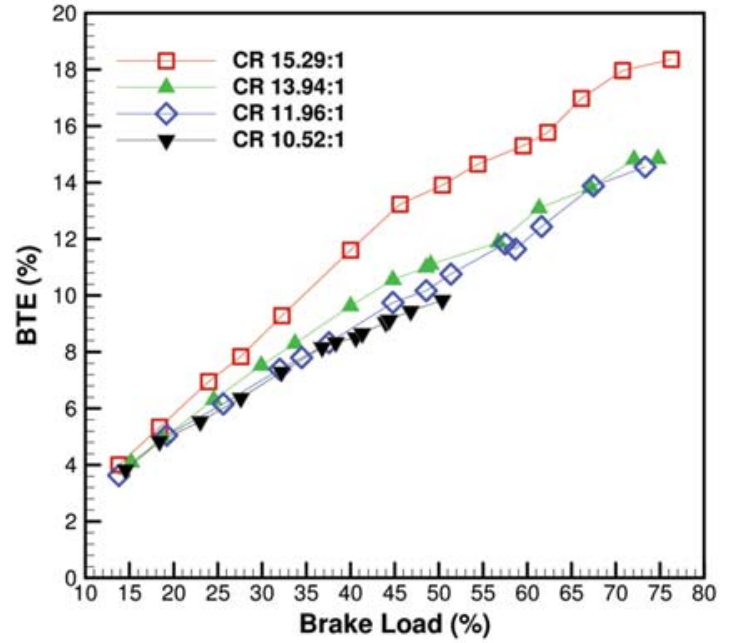

Fig. 6 Effect of CR on the BTE of the engine

10.52 are found to be $1.15 \mathrm{~kg} / \mathrm{kWh}, 1.43 \mathrm{~kg} / \mathrm{kWh}, 1.46 \mathrm{~kg} / \mathrm{kWh}$ and $2.15 \mathrm{~kg} / \mathrm{kWh}$ at the brake loads of $76.2 \%, 74.8 \%, 73.3 \%$ and $50.4 \%$, respectively. At a particular loading condition (50\% brake load) increasing the $\mathrm{CR}$ form 10.52 to $11.96,11.96$ to 13.94 and 13.94 to 15.29 reduced the BSFC by $8.37 \%, 4 \%$ and $21 \%$, respectively. This because, with increasing $\mathrm{CR}$, the rate of rise in $\mathrm{BP}$ is lesser than the rate of drop in mass of fuel consumed and the mass fuel consumed to generate unit BP is comparatively lesser than at lower CRs. Hence, The BSFC is reduced with increased $\mathrm{CR}$.

The variation of brake thermal efficiency (BTE) of the engine along with progressive advancement of the developed brake load at different operating CRs are shown in Fig. 6. It was observed that, irrespective CR the BTE of the engine follows an increasing trend along with increasing brake load of the engine. Since, at all operating CRs the BSFC of the engine follows a decreasing trend against the developed brake load of the engine; the BTE is following an opposite trend. It was also observed that the BTE follows an increasing trend along with increasing compression ratio of the engine. This is because; along with increasing CR the BP of the engine increases and decreases the fuel consumption rate. The engine operated at CR 15.29 showed the maximum BTE of $18.35 \%$ at $76.2 \%$ of developed brake load. However, the maximum brake thermal efficiencies of the engine operated at CR 13.94, CR 11.96 and CR 10.52 are found to be $14.84 \%, 14.55 \%$ and $9.83 \%$, respectively. Increasing the operating CR from 10.52 to $11.96,11.96$ to 13.94 and 13.94 to 15.92 enhanced the BTE of the engine by $48 \%, 2 \%$ and $23.6 \%$, respectively.

Figure 7 shows the variation of the volumetric efficiency of the biogas fuelled SI engine against the developed brake load when operated with in $\mathrm{CR}$ ranging from 10.52 to 15.29 . It was observed that, irrespective of $\mathrm{CR}$, the volumetric efficiency of the engine follows an increasing trend along with progressive development of the engine load. This is due to the

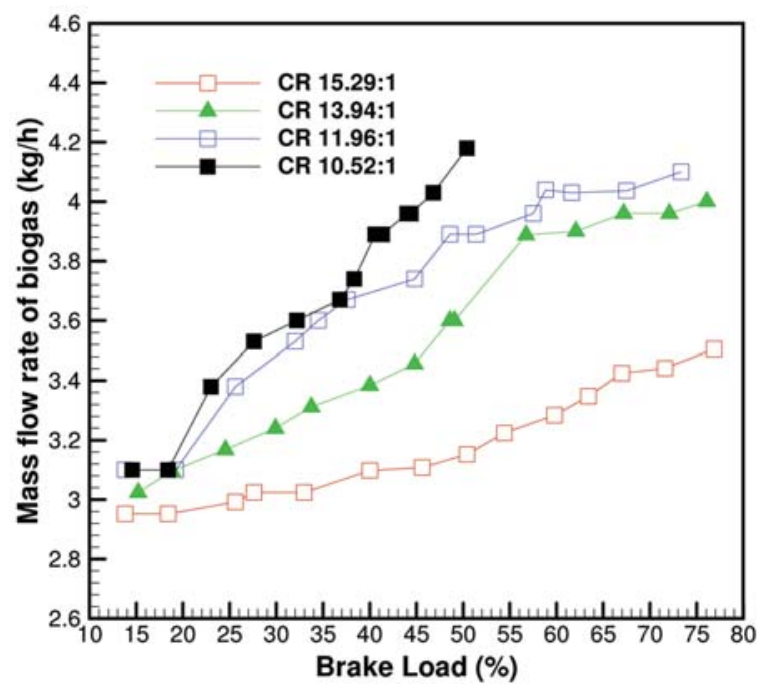

Fig. 7 Effect of $\mathrm{CR}$ on the fuel consumption rate fact that along with increasing brake load, mass flow rate of fuel consumed is being increased which interns induce more air to combustion chamber. It was also observed that with along with increasing $\mathrm{CR}$ the volumetric efficiency of the engine follows a decreasing trend. The volumetric efficiencies of the engine operated at CR 10.52, CR 11.96, CR 13.94 and CR 15.29 are found to very between $34.6-51.1 \%, 32.7-48.8 \%, 29.1$ $48.3 \%$, and $28.7-32.7 \%$ respectively. The maximum volumetric efficiency was observed at CR 10.52 .

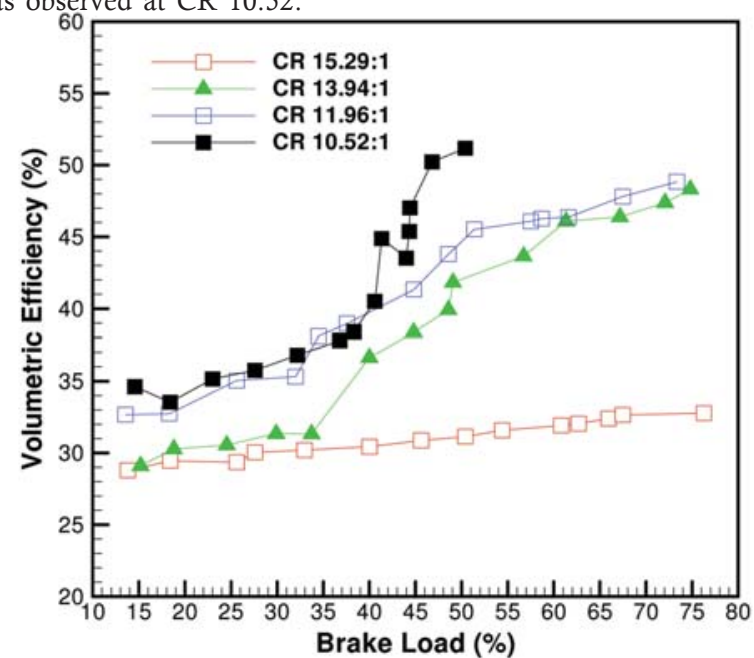

Fig. 8 Effect of $\mathrm{CR}$ on the volumetric efficiency of the engine

\subsection{Emission analysis}

Carbon monoxide (CO) forms partially due to deficiency of oxygen in the fuel air mixture leading to incomplete combustion. In the current investigation as depicted in Fig. 9 the $\mathrm{CO}$ emission decreases with increasing $\mathrm{CR}$ of the engine. The reason that could fit may be the increased amount of fuel mass consumed at lower CRs, which could not burnt completely due deficiency of oxygen and do not allow the $\mathrm{CO}$ to be oxidized. However, with increasing CR the flame front propagation becomes faster and consumes enough biogas-air mixture to bring down the $\mathrm{CO}$ level. It was also observed that, the $\mathrm{CO}$ emission follows an increasing trend along with progressive development of brake load of the engine. The minimum $\mathrm{CO}$ emission was observed at CR 15.29 and found to very between 0.016 to $0.091 \%$. The maximum CO emission was found at CR 10.52 and very between 0.022 to $0.17 \%$.

The variation of hydrocarbon emission at different CRs of the biogas fuelled SI engine is shown in Fig. 10. It was observed that HC content in exhaust emission of the biogas fuelled SI engine was decreased with increased $\mathrm{CR}$ of the engine. It was also observed that with increasing brake load the $\mathrm{HC}$ emission was increased. Irrespective of engine loading condition, the minimum HC emission was observed at CR 15.29 and was found very between 23-144 ppm.

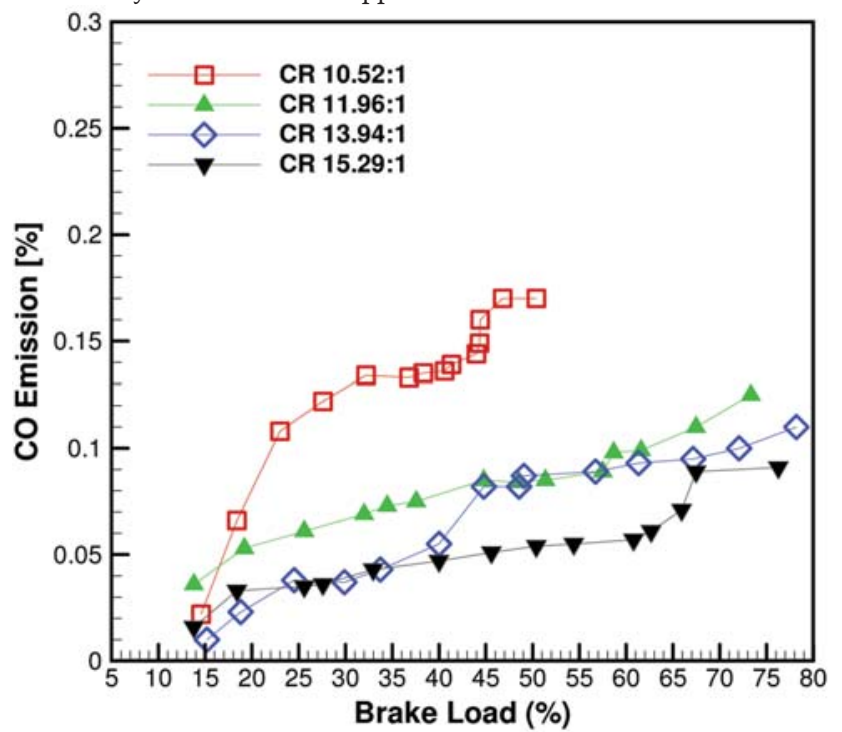

Fig. 9 Effect of $\mathrm{CR}$ on the carbon monoxide emission of the biogas fueled SI engine 


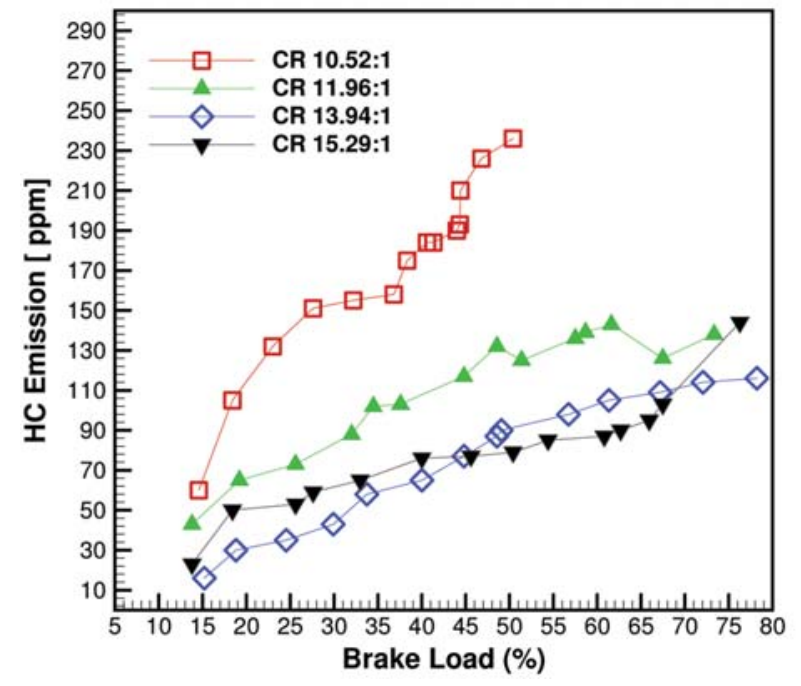

Fig. 10 Effect of $C R$ on the hydrocarbon emission of the biogas fueled SI engine

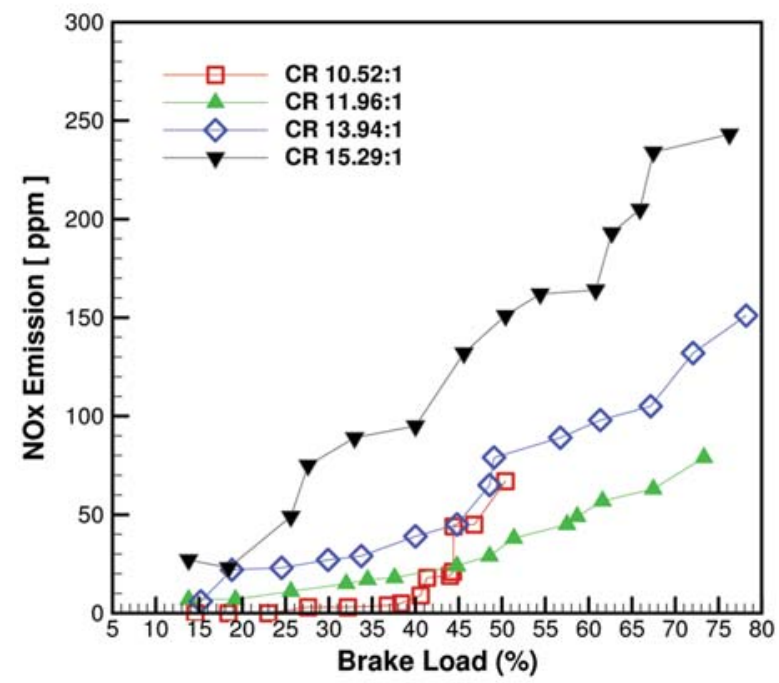

Fig. 11 Effect of $\mathrm{CR}$ on the nitric oxide emission of the biogas fueled SI engine

Figure 11, shows the effect of compression ratio on the NO emission of a biogas fuelled SI engine. It was observed that with increasing $\mathrm{CR}$ and brake load on the engine the $\mathrm{NO}_{x}$ concentration in the exhaust emission of the biogas fuelled SI engine follows an increasing trend. The maximum $\mathrm{NO}_{\mathrm{x}}$ emission was detected at CR 15.29 and was found to very between $27-240 \mathrm{ppm}$. The $\mathrm{NO}_{\mathrm{x}}$ emission is strongly related to the lean fuel with high cylinder temperature or high combustion temperature. The cylinder temperature and combustion temperature increases with increasing $\mathrm{CR}$ and is higher in case of CR 15.29 as compared to other CRs. Because of this reason only the $\mathrm{NO}_{\mathrm{x}}$ concentration is comparatively higher in $\mathrm{CR}$ 15.29 .

\section{Conclusions}

Based on the experimental investigation carried out to investigate the effect of CR on the performance and emission characteristics of the raw biogas fueled, constant speed SI engine, the following conclusions are drawn.

Higher CR increases the mean gas temperature MGT and initiates the complete combustion which leads to higher energy conversion efficiency and develops more power.

With increasing CR the maximum BP output of the engine was increased along with enhanced brake load carrying capacity of the engine. With a maximum brake load development of $76.27 \%$, the brake power output of the engine was found maximum $(2.93 \mathrm{~kW})$, when operated at CR 15.29. With increasing CR the engine becomes more stable and operated with an appreciable deviation in speed. he biogas engine operating with CR 15.29 revealed the minimum BSFC $(1.15 \mathrm{~kg} / \mathrm{kWh})$ and the maximum BTE (18.35\%) at $76.2 \%$ of brake load.

The $\mathrm{CO}$ and $\mathrm{HC}$ concentration in the exhaust emission decreases with increasing $\mathrm{CR}$ of the engine. The minimum $\mathrm{CO}$ and $\mathrm{HC}$ emission were observed at CR 15.29 and found to very between 0.016 to $0.091 \%$. and 23-144 ppm, respectively. With increasing CR and brake load on the engine the $\mathrm{NO}_{\mathrm{x}}$ concentration in the exhaust emission of the biogas fuelled SI engine follows an increasing trend. The maximum $\mathrm{NO}_{x}$ emission was detected at CR 15.29 and was found to very between 27-240 ppm.

\section{Acknowledgments}

The authors wish to thank the Ministry of New and Renewable Energy (MNRE) for the financial support in doing this project.

\section{References}

[1]. Alagumalai, A. (2014) Internal combustion engines: Progress and prospects Renewable and Sustainable Energy Review, 38:5, pp. 61-71.

[2]. Chandra R, Vijay V. K., Subbarao P. M. and Khura T. K. (2011) Performance evaluation of a constant speed IC engine on CNG, methane enriched biogas and biogas, Applied Energy, 30;88 (11), pp. 3969-77.

[3]. Corti, E., Cavina, N., Cerofolini, A., Forte, C., Mancini, G., Moro, D., Ponti, F. and Ravaglioli, V. (2014) Transient spark advance calibration approach, Energy Procedia, 45, pp.967-976.

[4]. Crookes, R. J. (2006) Comparative bio-fuel performance in internal combustion engines, Biomass and Bioenergy, 30(5), pp. 461-468.

[5]. Hotta S. K, Singh R., Sahoo N., Mohanty K. and Mahanta P. (2015) Design of a venturi type biogas mixer for a four stroke spark ignition engine. Proceedings of the 5th International Conference on Advances in Energy Research, pp. 998-1005.

[6]. Huang, J. and Crookes R. J. (1998) "Assessment of simulated biogas as a fuel for the spark ignition engine, Fuel. 77(15), pp. 1793-1801.

[7]. Kapdi, S. S. (2005). Development of biogas enrichment and compression system for rural energy supply. PhD thesis, Center for Rural Technology, Indian Institute of Rural Technology Delhi.

[8]. Mitzlaff, V. (1988) Engines for Biogas- theory, modification, economic operation, A publication of Deutsches Zentrum fur Entwicklungstechnologien, GTZ - GATE, Germany.

[9]. Nathan S. S., Mallikarjuna J. M. and Ramesh A. (2010) An experimental study of the biogas-diesel HCCI mode of engine operation, Energy Conversion and Management. 31; 51 (7), pp. 1347-53.

[10]. Porpatham, E., Ramesh, A. and Nagalingam, B. (2007) Effect of hydrogen addition on the performance of a biogas fuelled spark ignition engine, International Journal of Hydrogen Energy, 32(12), pp.2057-2065.

[11]. Porpatham, E., Ramesh, A. and Nagalingam, B. (2008) Investigation on the effect of concentration of methane in biogas when used as a fuel for a spark ignition engine, Fuel, 87.8, pp. 1651-1659.

[12]. Porpatham, E., Ramesh, A. and Nagalingam, B. (2012) Effect of compression ratio on the performance and combustion of a biogas fuelled spark ignition engine, Fuel, 95, pp. 247-256.

[13]. Porpatham, E., Ramesh, A. and Nagalingam, B. (2013) Effect of swirl on the performance and combustion of a biogas fuelled spark ignition engine, Energy Conversion and Management, 76, pp. 463-471

[14]. Surata, I. W., Nindhia, T. G.T., Atmika, I. K. A., Negara, D. N. K. P and Putra, I.W E. P. (2014) Simple Conversion Method from Gasoline to Biogas Fueled Small Engine to Powered Electric Generator, Energy Procedia, 52, pp. 626-632. 